\title{
Electronic Transport in Low-Temperature Silicon Nitride
}

\author{
P. Alpuim ${ }^{1,2}$, P. Ferreira ${ }^{1}$, V. Chu ${ }^{1}$, J.P. Conde ${ }^{2}$ \\ ${ }^{1}$ Instituto de Engenharia de Sistemas e Computadores (INESC), 1000-029 Lisboa, Portugal \\ ${ }^{2}$ Dept. of Materials Engineering, Instituto Superior Técnico (IST), 1049-001 Lisboa, Portugal
}

\begin{abstract}
Perpendicular current transport through thin silicon nitride films deposited at $100{ }^{\circ} \mathrm{C}$ by radio frequency chemical vapor deposition is measured between patterned square contacts with side lengths between 5 and $200 \mu \mathrm{m}$. Hydrogen dilution, silane-to-ammonia ratio, and total gas flow were varied to achieve control of film properties. The dependence of the current on the applied field and measurement temperature are correlated to structural parameters such as the index of refraction, etching rate in buffered hydrofluoric acid and infrared vibrational band strengths. Using the appropriate deposition parameters, it is possible to prepare at $100{ }^{\circ} \mathrm{C}$ silicon nitride dielectric films with electronic properties compatible with its use as gate dielectrics of thin-film transistors.
\end{abstract}




\section{Introduction}

Applications of functional devices and electronic circuits on flexible, light and inexpensive substrates, such as plastic, have attracted much recent interest. Development of a process for the fabrication of thin film transistors at temperatures at or below $100{ }^{\circ} \mathrm{C}$ would make possible the use of inexpensive plastic substrates. Of the process steps involved in the fabrication of thin film transistors, silicon nitride deposition is usually the limiting factor in the lowering of the device processing temperature. Silicon nitride optimized for good dielectric characteristics, such as high resistivity $\left(10^{14} \Omega \mathrm{cm}\right.$, or $3 \times 10^{-8} \mathrm{Acm}^{-2}$ at $\left.3 \mathrm{MVcm}^{-1}\right)$, high breakdown field $\left(10 \mathrm{MVcm}^{-1}\right)$, low hydrogen content $(\sim 12 \%)$ and correct stoichiometry (N/Si ratio: 1.33$)$ generally requires deposition temperatures at or above $300{ }^{\circ} \mathrm{C}$ [1]. $\mathrm{SiN}_{\mathrm{x}}$ films with properties approaching those of high temperature films have been prepared at low temperature $\left(100-125^{\circ} \mathrm{C}\right)$ by rf magnetron sputtering [2], by electron-cyclotron resonance plasma-enhanced chemical vapor deposition (ECR-PECVD) [3] and by RF PECVD [4].

For TFT applications, characterizing and minimizing the leakage current through the dielectric as a function of the applied electric field is of great importance. To obtain an accurate I-V curve across a thin dielectric (1000-3000 $\AA$ ) it is indispensable to ensure that the film is pinhole free. In this paper, cleanroom patterned square contacts with side lengths between 5 and $200 \mu \mathrm{m}$ are used to minimize the effects of pinholes by reducing the area of the contacts used for perpendicular transport measurements. 


\section{Experimental procedures}

The $\mathrm{SiN}_{\mathrm{x}}$ films were deposited by radio frequency chemical vapor deposition (RF). For all samples studied, the substrate temperature was $100^{\circ} \mathrm{C}$, the deposition pressure was $0.1 \mathrm{Torr}$, and the RF power was $10 \mathrm{~W}$ (corresponding to a power density of $\sim 100 \mathrm{mWcm}^{-2}$ ). Silane, ammonia and hydrogen were the source gases used. The index of refraction was measured using ellipsometry at $633 \mathrm{~nm}$. The etch rate was evaluated from the dependence of the thickness of the film (measured with a profilometer) on the immersion time in 10\% buffered HF. Infrared spectra, which give information regarding the hydrogen and $\mathrm{Si}-\mathrm{N}$ bonding in the $\mathrm{SiN}_{\mathrm{x}}$ films [5] were measured using a FTIR spectrometer.

$\operatorname{Al}(1500 \AA) / \operatorname{TiW}(150 \AA) / \operatorname{SiN}_{\mathrm{x}}(3000 \AA) / \mathrm{Al}(1500 \AA) \mathrm{MIM}$ microstructures were fabricated. The structures were patterned with direct write optical lithography using a HeCd laser at $442 \mathrm{~nm}$. The MIM structures are defined by the overlap of the Al contacts, which forms squares with side lengths between 5 and $200 \mu \mathrm{m}$. Current-voltage curves were measured as a function of the temperature (between room temperature and $90^{\circ} \mathrm{C}$ ) by applying a voltage between the top and bottom contacts (at a rate of $\sim 1 \mathrm{~V} / \mathrm{s}$ ).

\section{Results}

Three series of samples were prepared, in which the hydrogen dilution (the ratio of the flux of hydrogen to the total gas flow), the flow ratio (defined as the ammonia-to-silane gas flow ratio), and the total gas flow were varied, respectively, while keeping the other deposition parameters 
constant. Table I summarises the deposition conditions and the properties of the samples studied. All films studied were transparent in the visible. All the deposition variables studied affect the silicon-to-nitrogen content in the films. Increasing either the hydrogen dilution or the flow ratio increases the N-to-Si ratio in the film, while increasing the total flux of gases decreases the N-toSi ratio. This can be observed in figure 1, where the ratio of the integrated absorption of the N-H (around $3300 \mathrm{~cm}^{-1}$ ) to the $\mathrm{Si}-\mathrm{H}$ (around $2100 \mathrm{~cm}^{-1}$ ) stretching bands, $\mathrm{R}_{\mathrm{NH} / \mathrm{SiH}}$, is plotted as a function of deposition parameters. The integrated absorption of the $\mathrm{Si}-\mathrm{H}$ has been divided by a factor of 1.4 to take into account the difference in oscillator strength of these two vibrations [5]. Samples with $\mathrm{R}_{\mathrm{NH} / \mathrm{SiH}}$ below unity have, in general, values of index of refraction at or above 1.85 and etch rates below $100 \AA$ /s, typical of Si-rich films. Samples with $\mathrm{R}_{\mathrm{NH} / \mathrm{SiH}}$ above unity have indices of refraction below 1.85 and etch rates above $100 \AA / \mathrm{s}$, typical of $\mathrm{N}$-rich films. A connection between $\mathrm{R}_{\mathrm{NH} / \mathrm{SiH}}$ and $\mathrm{N} / \mathrm{Si}$ has been previously observed, and $\mathrm{N}-\mathrm{H} / \mathrm{Si}-\mathrm{H}$ ratios between 0.2 and 2.0 have been shown to give near stoichiometric dielectrics with good electronic properties [4]. Note that in the films studied no value of $\mathrm{R}_{\mathrm{NH} / \mathrm{SiH}}$ between 1 and 2 was obtained. The increase in hydrogen dilution increases the electron energy in the plasma, which in turn aids the decomposition of ammonia, and increases the incorporation of $\mathrm{N}$ correspondingly. The increase in residence time resulting from the decrease of total gas flow also increases $\mathrm{N}$ incorporation in the film.

In general, the current density-electric field curves, J-E, of $\mathrm{SiN}_{\mathrm{x}}$ films deposited at $100{ }^{\circ} \mathrm{C}$ show ohmic behaviour in the low-field regime at room temperature. The ohmic region is followed, at higher applied fields, by a region of rapidly increasing J. Table I lists the electrical conductivity in the ohmic region, $\sigma$ (ohmic), and also the field at which $\mathrm{J}$ starts increasing superlinearly, 
Einjection. For samples with $\mathrm{R}_{\mathrm{NH} / \mathrm{SiH}}<1$, an increase of $\mathrm{R}_{\mathrm{NH} / \mathrm{SiH}}$, and, consequently, of the $\mathrm{N} / \mathrm{Si}$ ratio in the film, has as its main consequence an increase of $E_{\text {injection }}$ and a corresponding increase in the breakdown voltage (figure 2 (a)). For samples with $\mathrm{R}_{\mathrm{NH} / \mathrm{SiH}}<0.2$, the breakdown voltage is typically below $5 \mathrm{MVcm}^{-1}$, while for samples with $0.2<\mathrm{R}_{\mathrm{NH} / \mathrm{SiH}}<1$, the breakdown voltage is typically above $10 \mathrm{MVcm}^{-1}$. For $\mathrm{N}$-rich samples $\left(\mathrm{R}_{\mathrm{NH} / \mathrm{SiH}}>2\right)$, the same shape of the J-E curve is obtained at room temperature, although the conductivity in the ohmic region tends to be slightly

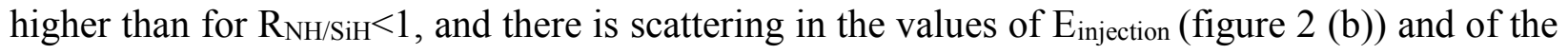
breakdown voltage.

Samples with $\mathrm{R}_{\mathrm{NH} / \mathrm{SiH}}<1$ and $\mathrm{R}_{\mathrm{NH} / \mathrm{SiH}}>2$ exhibit very different and reproducible temperature dependent behavior. Fig. 3 shows J-E curves for typical samples with $\mathrm{R}_{\mathrm{NH} / \mathrm{SiH}}<1$ (fig. 3 (a)) and $\mathrm{R}_{\mathrm{NH} / \mathrm{SiH}}>2$ (fig. 3 (b)) measured at different temperatures. For the Si-rich sample $\left(\mathrm{R}_{\mathrm{NH} / \mathrm{SiH}}<1\right.$, fig. 3 (a)), there is a very small temperature dependence of $\mathrm{J}$ in the ohmic region for temperatures up to $75{ }^{\circ} \mathrm{C}$ with activation energy of $\mathrm{J}$ below $0.1 \mathrm{eV}$. Only at $90{ }^{\circ} \mathrm{C}$ is a significant increase in $\mathrm{J}$ observed for the sample shown in fig. 3(a). In the superlinear region at higher applied fields, J is essentially temperature independent, with activation energy below $0.1 \mathrm{eV}$. For the $\mathrm{N}$-rich sample $\left(\mathrm{R}_{\mathrm{NH} / \mathrm{SiH}}>2\right.$, fig. 3 (b)), in the low-field region, there is a significant temperature dependence of $\mathrm{J}$, with activation energy above $0.4 \mathrm{eV}$. At higher values of $\mathrm{T}\left(>60{ }^{\circ} \mathrm{C}\right)$ ohmic behavior is no longer observed, and instead only one superlinear region exists for all the range of applied fields. 


\section{Discussion}

Transport in $\mathrm{SiN}_{\mathrm{x}}$ films is usually discussed in terms of three main transport mechanisms: (i) ohmic conduction; (ii) Frenkel-Poole conduction; and (iii) Fowler-Nordheim conduction [6-8]. Ohmic conduction, which corresponds to hopping of trapped electrons, typically occurs at low fields and moderate temperatures. Frenkel-Poole conduction typically occurs at high fields and high temperatures. This process is usually strongly temperature-dependent. Fowler-Nordheim conduction typically occurs at high fields and low temperatures. Fowler-Nordheim conduction, being a tunneling process, is essentially temperature independent.

Silicon-rich $\mathrm{SiN}_{\mathrm{x}}$ films $\left(\mathrm{R}_{\mathrm{NH} / \mathrm{SiH}}<1\right)$ show ohmic conduction at low applied fields up to a transition field, Einjection after which a temperature-independent tunneling process dominates. $\mathrm{E}_{\text {injection }}$ moves to higher values as $\mathrm{R}_{\mathrm{NH} / \mathrm{SiH}}$ approaches unity, suggesting that films with $\mathrm{R}_{\mathrm{NH} / \mathrm{SiH} \sim 1}$ have fewer silicon dangling bonds and other defects than films with lower values of $\mathrm{R}_{\mathrm{NH} / \mathrm{SiH}}$. Nitrogen-rich $\mathrm{SiN}_{\mathrm{x}}$ films $\left(\mathrm{R}_{\mathrm{NH} / \mathrm{SiH}}>2\right)$ show, at room temperature, ohmic conduction at low applied fields. This regime is followed, after Einjection, of a superlinear increase in J vs. E. The J-E behavior of these films is highly temperature dependent suggesting that Frenkel-Poole conduction dominates at moderate temperatures $\left(>60 \quad{ }^{\circ} \mathrm{C}\right)$, already making significant a contribution to the current even at room temperature. This is consistent with a larger density of traps for Frenkel-Poole emission in N-rich $\mathrm{SiN}_{\mathrm{x}}$ and can be attributed to a combination of Ndangling bonds with $\mathrm{N}-\mathrm{N}$ bonds as suggested by Yan et al. [9]. 


\section{Conclusions}

Current transport through low deposition temperature $\mathrm{SiN}_{\mathrm{x}}$ is controlled by ohmic conduction at low applied fields. At high fields, temperature dependence of I-V measurements show that conduction is dominated by Fowler-Nordheim tunneling in the case of silicon rich films and by Frenkel-Poole conduction in the case of nitrogen-rich films. The field at which the conduction ceases to be ohmic is highly dependent on film composition and deposition conditions.

It is possible to optimize the deposition of $\mathrm{SiN}_{\mathrm{x}}$ dielectric films at $100{ }^{\circ} \mathrm{C}$ to produce films compatible with its use as dielectric layers of thin-film transistors prepared on inexpensive plastic substrates or other temperature-sensitive materials. These films show: (i) ohmic conductivity at low applied fields below $5 \times 10^{-15} \Omega^{-1} \mathrm{~cm}^{-1}$ (corresponding to a resistivity above $10^{14} \Omega^{-1} \mathrm{~cm}^{-1}$ ); (ii) current density below $10^{-8} \mathrm{Acm}^{-2}$ at $3 \mathrm{MVcm}^{-1}$; (iii) injection field above 5 $\mathrm{MVcm}^{-1}$; and (iv) breakdown field above $10 \mathrm{MVcm}^{-1}$.

\section{Acknowledgements}

This work was supported by the FCT through Pluriannual Contracts with ICEMS (IST) and INESC and through PRAXIS and POCTI projects. P.A. thanks the Physics Dept., University of Minho for a leave of absence. 


\section{References}

[1] W.S. Lau, S. Fonash, J. Kanicki, J. Appl. Phys. 66 (1989) 2765.

[2] C.S. McCormick, C.E. Weber, J.R. Abelson, Appl. Phys. Lett. 70 (1997) 226.

[3] F.S. Pool, J. Appl. Phys. 81 (1997) 2839.

[4] T.M. Klein, T.M. Anderson, A.I. Chowdhury, G.N. Parsons, J. Vac. Sci. Technol. A 17 (1999) 108.

[5] W.A. Lanford, M.J. Rand, J. Appl. Phys. 49 (1978) 2473.

[6] S.M. Sze, J. Appl. Phys. 38 (1967) 2951.

[7] S.N. Mohammad, M. Tao, D.G. Park, A.E. Botchkarev, D. Li, H. Morkoç, Phil. Mag. B 73 (1996) 817.

[8] G.N. Parsons, J.H. Souk, J. Batey, J. Appl. Phys. 70 (1991) 1553.

[9] H. Yan, M. Kumeda, N. Ishii, T. Shimizu, Jpn. J. Appl. Phys. 32, 876 (1993). 


\section{Figure captions}

Figure 1. Ratio of the integrated absorption stretching peaks of the $\mathrm{N}-\mathrm{H}$ and $\mathrm{Si}-\mathrm{H}$ vibrations corrected for oscillator strength difference, $\mathrm{R}_{\mathrm{NH} / \mathrm{SiH}}$, plotted as a function of: (a) hydrogen dilution; (b) ratio of ammonia to silane flows; and (c) total gas flow rate. The dotted line corresponds to $\mathrm{R}_{\mathrm{NH} / \mathrm{SiH}}=1$. Samples deposited by $\mathrm{RF}$ at $100^{\circ} \mathrm{C}$.

Figure 2. Current density, J, measured at room temperature and plotted as a function of the applied electric field, E, for selected $\mathrm{SiN}_{\mathrm{x}}$ samples: (a) shows characteristic J-E curves for $\mathrm{SiN}_{\mathrm{x}}$ samples with $\mathrm{R}_{\mathrm{NH} / \mathrm{SiH}}<1$, and (b) shows characteristic J-E curves for $\mathrm{SiN}_{\mathrm{x}}$ samples with $\mathrm{R}_{\mathrm{NH} / \mathrm{SiH}}>2$.

Figure 3. Current density, J, measured at different temperatures, T, plotted as a function of the applied electric field, E, for characteristic $\mathrm{SiN}_{\mathrm{x}}$ samples: (a) SN2002, with $\mathrm{R}_{\mathrm{NH} / \mathrm{SiH}}<1$; and (b) SN2005, with $\mathrm{R}_{\mathrm{NH} / \mathrm{SiH}}>2$. The inserts show values of $\mathrm{J}$ as a function of $1000 / \mathrm{T}$ for fixed applied fields. 
Figure 1. P. Alpuim et al.

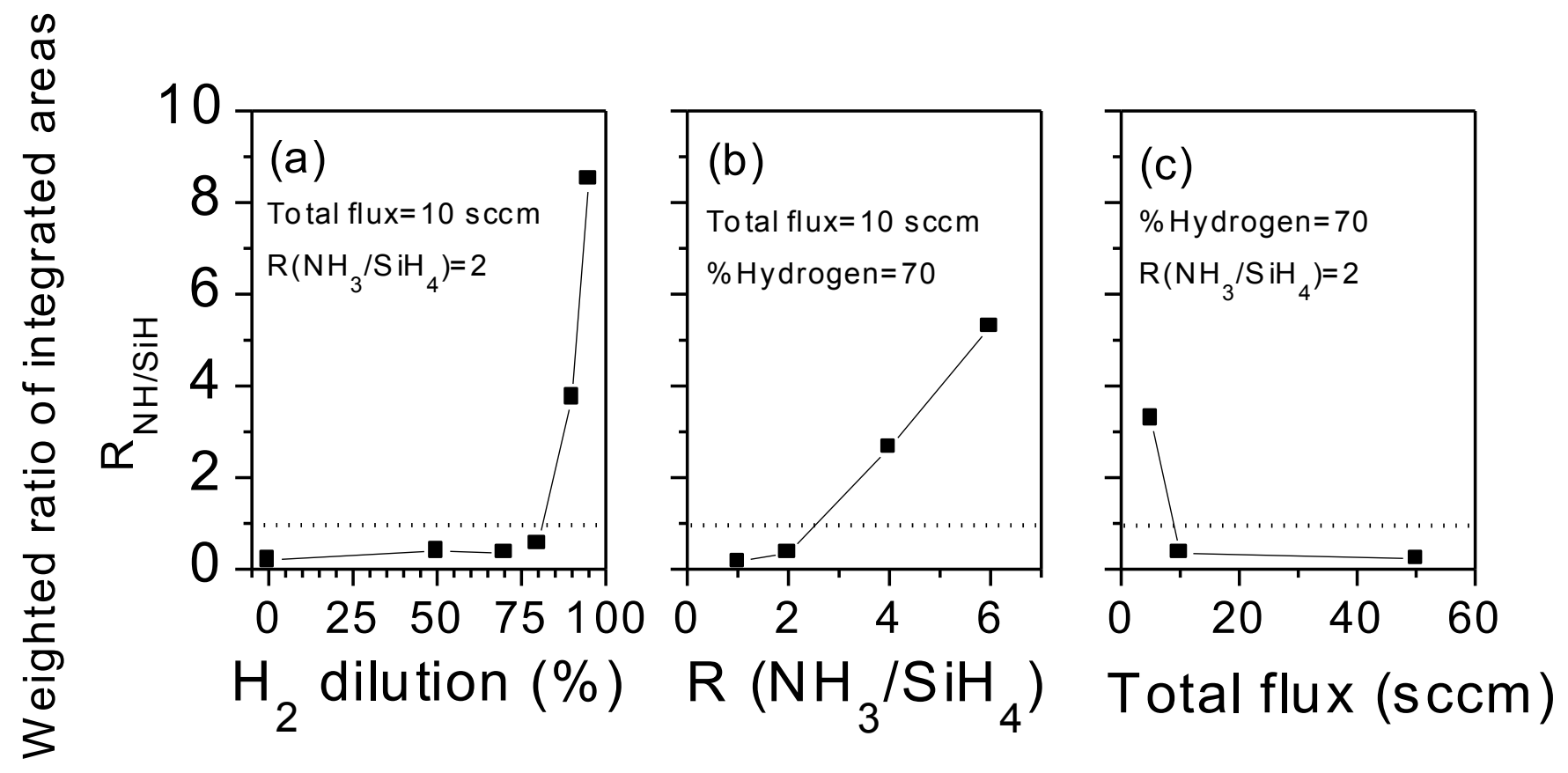


Figure 2. P. Alpuim et al.

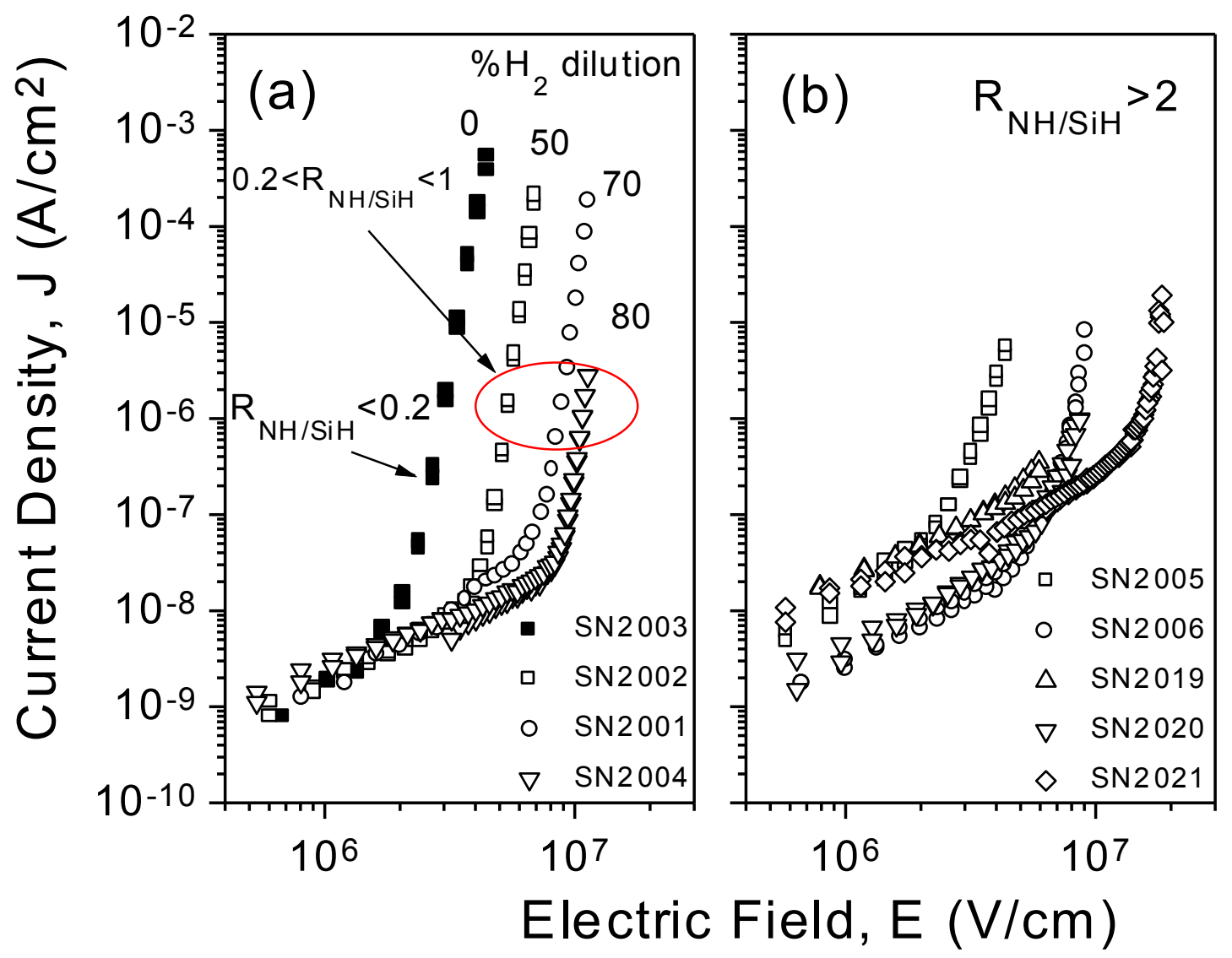


Figure 3. P. Alpuim et al.

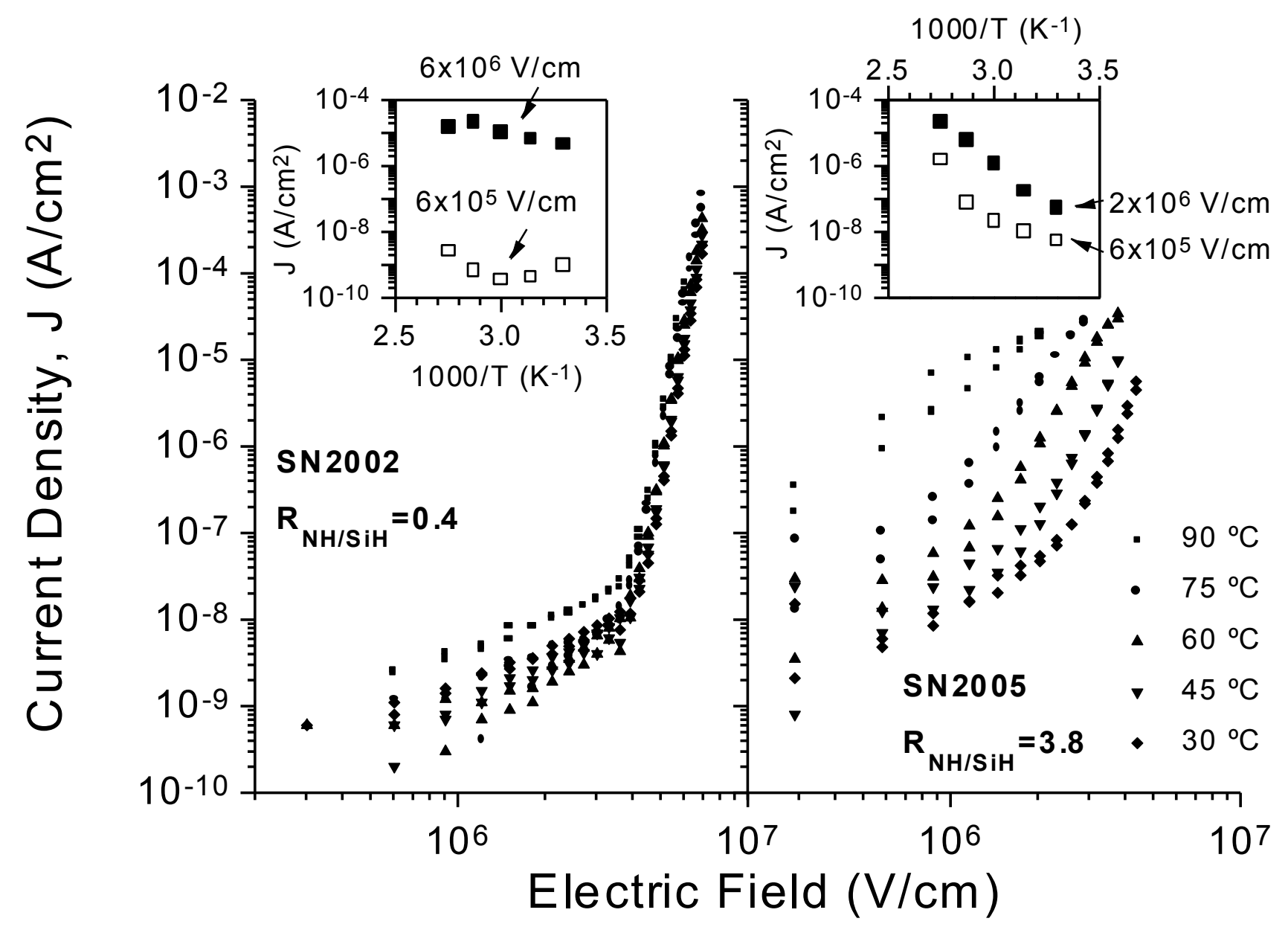

